\title{
Conhecimento de Estudantes de Medicina sobre o Funcionamento do Serviço de Atendimento Móvel de Urgência (Samu)
}

\author{
Knowlegdeof Medical Students about the \\ Functioning of the Mobile Emergency Medical \\ Service (SAMU)
}

\section{PALAVRAS-CHAVE \\ - Educação Médica; \\ - Educação de Graduação em Medicina; \\ - Sistemas de Comunicação entre Serviços de Emergência; \\ - Serviços Médicos de Emergência.}

\section{KEYWORDS}

- MedicalTraining;

- Undergraduate Medical Training;

- Communication Systems between Emergency Services;

- Emergency Medical Services.
Cláudia Regina Fernandes ${ }^{I}$ Sarah Barreira Cavalcante ${ }^{I}$ Juliana de Abreu Pinheiro José Victor Gomes Costal Pedro Lucas Rodrigues Costa ${ }^{I}$ Antônio Aldo Melo-Filho ${ }^{I}$

\section{RESUMO}

O presente estudo teve por objetivo avaliar o nível de conhecimento dos estudantes de Medicina sobre o funcionamento do Serviço de Atendimento Móvel de Urgência (Samu), dada a importância deste serviço para a população e seu papel fundamental no Sistema Único de Saúde (SUS). Para tanto, acadêmicos do primeiro ao $12^{\circ}$ semestre foram entrevistados mediante um questionário padronizado. Concluiu-se que mesmo acadêmicos de Medicina, indivíduos que se encontram imersos na área da saúde, possuem conhecimento aquém do esperado sobre o Samu, independentemente do período cursado, fazendo-nos questionar o conhecimento da população em geral sobre o tema e a importância da realização de novos estudos e comparação de dados em âmbito nacional.

\begin{abstract}
This study aimed to assessthe knowledge of medical students about the functioning of the pre-hospital emergency medical service (EMS), given the importance of this service to the population and its role in the Unified Health System (SUS). Therefore, first to sixth year students were interviewed using a standardized questionnaire. The conclusion was drawn that even medical students, individuals who are immersed in health, have an unsatisfying level of knowledge about the SAMU, regardless of the stage of their studies, leading us to query the knowledge of the general public about this service and the importance of conducting further studies and making comparisons of nationwide data.
\end{abstract}


Recebido em: 28/07/2013

Reencaminhado em: 17/05/2014

Aprovado em: 10/06/2014

\section{INTRODUÇÃO}

As políticas públicas do governo federal voltadas para a organização do atendimento pré-hospitalar de urgência remontam a 1998, com a publicação da Portaria GM/MS n 2.923. Esta determinou investimentos nas áreas de Assistência Pré-Hospitalar Móvel, Assistência Hospitalar, Centrais de Regulação de Urgências e Capacitação de Recursos Humanos. No entanto, os avanços seguintes ocorreram lentamente, até que, em 2003, foi publicada a "Política Nacional de Atenção às Urgências" (Portaria MS no $1.863 / 03$ ), que considerou a área de urgências prioritária no âmbito das ações do SUS. Seu produto consecutivo foi a instituição do componente pré-hospitalar móvel, por intermédio da implantação de Serviços de Atendimento Móvel de Urgência (Samu-192), suas Centrais de Regulação (Central Samu-192) e seus Núcleos de Educação em Urgência, em municípios e regiões de todo o território brasileiro (Portaria $\left.\mathrm{n}^{\mathrm{o}} 1.864 / 03\right)^{1}$.

O atendimento do Samu funciona 24 horas por dia e atua em ocorrências em ambiente pré-hospitalar (via pública ou não), dentro de uma área geográfica específica. O serviço acolhe os pedidos de ajuda médica de cidadãos acometidos por agravos agudos de natureza clínica, psiquiátrica, cirúrgica, traumática, obstétrica e ginecológica ${ }^{1}$.

Segundo a Regulamentação Médica das Urgências, o grau de urgência é diretamente proporcional à gravidade, à quantidade de recursos necessários para atender o caso e à pressão social presente na cena do atendimento, e inversamente proporcional ao tempo necessário para iniciar o tratamento ${ }^{1}$.

O acesso telefônico ao Samu é gratuito, através do número nacional 192. A ligação é acolhida e identificada por técnicos na Central de Regulação e, em seguida, a solicitação é avaliada pelo médico regulador. Este classifica o nível de urgência da situação e define qual o recurso necessário ao seu adequado atendimento. Este pode envolver desde um simples conselho médico até o envio de uma Unidade de Suporte Avançado de Vida (USA). Neste sentido, os profissionais do Samu auxiliam ou proveem atendimento de suporte básico e/ou avançado de vida consoante a gravidade da condição clínica. Em segunda instância, em caso de atendimento inicial no local, o Samu tem a função de transportar o paciente ao hospital mais próximo que detenha recursos capazes de atender adequadamente o agravo em questão. Por meio destas ações, busca-se reduzir o número de óbitos, o tempo de internação hospitalar e as possíveis sequelas decorrentes da falta de atendimento precoce ${ }^{2}$.

O Samu conta com equipe de profissionais que inclui: técnicos auxiliares de regulação médica (telefonista), médicos reguladores, médicos intervencionistas, controladores de frota e radioperadores, enfermeiros e socorristas ${ }^{1}$. 
Um dos primeiros territórios para a difusão do conhecimento sobre o funcionamento do Samu deveria ser o ambiente de formação dos profissionais de saúde. Neste sentido, os acadêmicos poderiam atuar como multiplicadores deste conhecimento junto à população leiga ${ }^{3}$.

O ensino de urgências na Faculdade de Medicina da Universidade Federal do Ceará (Famed-UFC) está contemplado em dois momentos: no primeiro semestre, no módulo de Assistência Básica à Saúde, no qual os alunos têm aulas teórico-práticas sobre primeiros socorros e Suporte Básico de Vida (BLS); e no oitavo semestre, quando os alunos têm um ensino mais amplo acerca de urgências e emergências clínicas, cirúrgicas e pediátricas, Suporte Avançado de Vida (ACLS), regulação médica e atendimento pré-hospitalar. Os estudantes contam ainda com vivência no cenário do Samu - Fortaleza, na forma de plantões. A despeito desses enfoques, entende-se que a universidade deveria interagir mais com o sistema.

A hipótese é que os estudantes de Medicina da Famed-UFC não dominam o funcionamento e a infraestrutura do Serviço Móvel de Atendimento de Urgências. Neste sentido, o objetivo foi avaliar o conhecimento dos alunos da graduação da Famed-UFC, campus Fortaleza, sobre a dinâmica de funcionamento do Samu e o atendimento de urgências e emergências em ambiente pré-hospitalar.

\section{MÉTODOS}

Trata-se de um estudo transversal, realizado na Faculdade de Medicina da Universidade Federal do Ceará (Famed-UFC) no primeiro semestre de 2010. A coleta de dados foi feita durante os intervalos das atividades acadêmicas mediante aplicação de formulários previamente elaborados. A população estudada foi composta de alunos devidamente matriculados na Famed-UFC, compreendendo estudantes do primeiro ao $12^{\circ}$ semestres. A escolha dos estudantes foi aleatória. Critérios de inclusão: ter idade superior a 18 anos e ter consentido em participar da pesquisa voluntariamente, mediante assinatura do termo de consentimento livre e esclarecido.Critérios de exclusão: ter idade inferior a 18 anos e não ser matriculado na Famed-UFC.

A coleta de dados foi realizada por quatro estudantes de Medicina devidamente calibrados para aplicar o referido questionário, constituído de nove quesitos com a proposta de avaliar o conhecimento dos alunos sobre o Samu, nos seguintes aspectos: informações necessárias ao acionar o serviço; dados fundamentais a serem fornecidos durante as ligações; infraestrutura (tipos e número de ambulâncias); profissionais que compõem as equipes de atendimento; locais atendidos pelo Samu na cidade de Fortaleza.
O projeto foi aprovado pelo Comitê de Ética em Pesquisa da Instituição, ofício n 22/10, protocolo n 27/10.

Para análise estatística, foi construído um banco de dados no programa Epiinfo versão 6.04.Os alunos entrevistados foram divididos em dois grupos: grupo 1,com aqueles que cursavam o ciclo básico de ensino (do primeiro ao quarto semestre), e grupo 2, correspondendo ao ciclo clínico (do quinto ao $12^{\circ}$ semestre). Na comparação entre os dois grupos utilizou-se o teste qui-quadrado mediante o programa GraphPadPrism 5.

\section{RESULTADOS}

A população total de alunos matriculados no ano de 2010 era de 960. Foi entrevistada uma amostragem de 122 discentes $(12,7 \%)$, sendo que 57 alunos $(46,72 \%)$ compuseram o grupo 1 (ciclo básico) e 65 alunos (53,28\%) o grupo 2 (ciclo clínico).

Foi questionado qual seria o número que aciona o Samu; 102 alunos (83,6\%) marcaram o quesito correto, escolhendo o número 192, não ocorrendo diferença estatisticamente significativa entre os grupos ( $\mathrm{p}=0,8660)$ (grupo $1: 84,21 \%$ versus grupo 2: $83,07 \%$ ) (Tabela 1 ).

Quanto ao número total de ambulâncias do Samu disponíveis em Fortaleza, que totalizava 25 no período das entrevistas, apenas quatro alunos acertaram, sendo todos pertencentes ao grupo ciclo básico (grupo 1: 7,54\% versus grupo: 2: 0\%; $\mathrm{p}=0,045)$ (Tabela 1).

A respeito do tipo de ambulâncias disponíveis para o atendimento à população (Unidade de Suporte Básico - USB e Unidade de Suporte Avançado de Vida - USA), esta questão foi corretamente respondida por 52 alunos, $42,6 \%$ do total, sendo $50,7 \%$ do grupo 1 versus 35,38\% do grupo 2 ( $p=0,0843$ ) (Tabela 1).

Quando indagados se todas as ambulâncias do Samu atendiam com médico, $81,15 \%$ responderam corretamente que não, sendo o percentual de acertos maior no grupo do ciclo clínico (grupo 1: 71,9\% versus grupo 2: 89,23\%; $p=0,0148$ ). (Tabela 2)

Apenas 17 alunos (13,9\%) responderam corretamente que cinco é o número de ambulâncias com médico que compõe a equipe de atendimento (grupo 1: 17,54\% versus grupo 2: $10,76 \% ; p=0,2810)$ e somente seis alunos $(4,91 \%)$ entrevistados responderam corretamente que a equipe de atendimento de uma Unidade de Suporte Avançado (UTI móvel) é composta por médico, enfermeiro e motorista, que também é socorrista (grupo 1: 7,01\% versus grupo 2: 3,07\%; $\mathrm{p}=0,4165$ ) (Tabela 2).

Os locais onde o Samu pode atender situações de urgência e emergência era do conhecimento de 103 alunos $(84,42 \%)$, que responderam corretamente à opção: pode 
atender em qualquer local, como residências, locais de trabalho e vias públicas (grupo 1: $91,22 \%$ versus grupo 2: $78,46 \%$; $\mathrm{p}=0,0524$ ) (Tabela 2).

TABELA 1

Acertos referentes a informações sobre o Samu

\begin{tabular}{lccc}
\hline & $\begin{array}{c}\text { Número de } \\
\text { contato do } \\
\text { Samu }\end{array}$ & $\begin{array}{c}\text { Número de } \\
\text { ambulâncias em } \\
\text { Fortaleza }\end{array}$ & $\begin{array}{c}\text { Número } \\
\text { de tipos de } \\
\text { ambulâncias }\end{array}$ \\
\hline Ciclo básico & $84,21 \%$ & $7,54 \%$ & $50,87 \%$ \\
Ciclo clínico & $83,07 \%$ & $0 \%$ & $35,38 \%$ \\
$\mathrm{p}$ & 0,866 & 0,045 & 0,0843 \\
\hline
\end{tabular}

TABELA 2

Acertos referentes a informações sobre o Samu

\begin{tabular}{lcccc}
\hline & $\begin{array}{c}\text { Todas as } \\
\text { ambulâncias } \\
\text { atuam com } \\
\text { médico? }\end{array}$ & $\begin{array}{c}\text { Quantas } \\
\text { ambulâncias } \\
\text { com médico } \\
\text { em seu } \\
\text { interior? }\end{array}$ & $\begin{array}{c}\text { Equipe de } \\
\text { atendimento } \\
\text { de uma USA }\end{array}$ & $\begin{array}{c}\text { Locais } \\
\text { em que o } \\
\text { Samu pode } \\
\text { atender }\end{array}$ \\
\hline Ciclo básico & $71,9 \%$ & $17,54 \%$ & $7,01 \%$ & $91,22 \%$ \\
Ciclo clínico & $89,23 \%$ & $10,76 \%$ & $3,07 \%$ & $78,46 \%$ \\
$\mathrm{p}$ & 0,0148 & 0,2810 & 0,4165 & 0,0524 \\
\hline
\end{tabular}

Quando se indagou sobre que informações seria necessário fornecer à técnica auxiliar de regulação médica (telefonista) ao acionar o Samu, nenhum dos alunos forneceu a resposta correta espontaneamente, que seria: nome do solicitante, número de telefone para contato, endereço da ocorrência, estado da vítima, número de vítimas e capacidade de prestar os primeiros socorros. Ao se avaliar cada resposta espontânea individualmente, constatou-se que os alunos do ciclo clínico citaram mais vezes que seria necessário informar o nome do solicitante $(p=0,0107 ; O R=3,511)$ e o endereço da ocorrência $(\mathrm{p}=0,0205 ; \mathrm{OR}=2,349)$ quando comparados aos alunos do ciclo básico (Tabela 3). Contudo, quando indagados sobre a mesma questão de forma direta, com o entrevistador fornecendo as informações para que o estudante respondesse apenas sim ou não, 76 discentes $(62,29 \%)$ responderam corretamente, sendo o percentual de acertos maior entre o grupo clínico $(50,87 \%$ grupo 1 versus $72,30 \%$ grupo $2 ; \mathrm{p}=0,0148)$. Neste quesito, quando avaliada cada resposta individualmente, o nome do solicitante foi mais frequentemente citado como informação necessária pelos alunos do grupo $2(\mathrm{p}=0,0012$; $\mathrm{OR}=$ 3,704) (Tabela 4).
TABELA 3

Informação necessária ao técnico de regulação (telefonista) do Samu - resposta espontânea.

\begin{tabular}{lcrr}
\hline \multicolumn{1}{c}{ Resposta Espontânea } & $\begin{array}{c}\text { Ciclo clínico } \\
(\mathbf{n}=\mathbf{6 5})\end{array}$ & $\begin{array}{c}\text { Ciclo básico } \\
(\mathbf{n}=\mathbf{5 7})\end{array}$ & \multicolumn{1}{c}{$\mathbf{p}$} \\
\hline $\begin{array}{l}\text { Nome do solicitante } \\
\text { Número do telefone para }\end{array}$ & 19 & 6 & $\begin{array}{r}0,0107 \\
(\mathrm{OR}: 3,511)\end{array}$ \\
$\begin{array}{l}\text { Contato } \\
\text { Estado da vítima }\end{array}$ & 7 & 4 & 0,5399 \\
& 58 & 49 & 0,5836 \\
Endereço da ocorrencia & 41 & 24 & $(\mathrm{OR}: 2,349)$ \\
Capacidade de prestar & & & 0,0205 \\
socorro & 5 & 4 & 1 \\
\hline
\end{tabular}

TABELA 4

Informação necessária ao técnico de regulação (telefonista) do Samu - resposta estimulada.

\begin{tabular}{lcrr}
\hline \multicolumn{1}{c}{ Resposta Espontânea } & $\begin{array}{c}\text { Ciclo clínico } \\
(\mathbf{n}=\mathbf{6 5})\end{array}$ & $\begin{array}{c}\text { Ciclo básico } \\
(\mathbf{n}=\mathbf{5 7})\end{array}$ & \multicolumn{1}{c}{$\mathbf{p}$} \\
\hline Nome do solicitante & 53 & 31 & 0,0012 \\
Número do telefone para & & $57,704)$ \\
$\begin{array}{l}\text { contato } \\
\text { Estado da vítima }\end{array}$ & 64 & 56 & 1 \\
Endereço da ocorrencia & 64 & 57 & 0,6 \\
$\begin{array}{l}\text { Capacidade de prestar } \\
\text { socorro }\end{array}$ & 60 & & \\
\hline
\end{tabular}

Quanto à informação "número de vítimas" aser dada à telefonista auxiliar, este dado não foi investigado entre os alunos.

\section{DISCUSSÃO}

Este estudo demonstrou a fragilidade acerca dos conhecimentos dos estudantes de Medicina da Famed-UFC sobre das informações necessárias ao acionar o Samu, como também o desconhecimento do funcionamento deste serviço, que é uma das maiores portas de entrada para o Sistema Único de Saúde (SUS). Esta evidência se mostra inquietante, pois o conhecimento sobre o Samu é imprescindível para que a população faça bom uso e se beneficie desse serviço, sabendo como agir ao presenciar uma ocorrência que necessite de atendimento médico de urgência ${ }^{4,5}$. Os resultados deste estudo são preocupantes, pois a população que mais deveria entender sobre 
o desempenho desse serviço, que são os médicos em formação, não detém este conhecimento. Muito provavelmente, a população em geral compreende menos ainda, acarretando mau uso ou disfunção desse tipo de serviço. Além disso, acadêmicos de Medicina podem funcionar como multiplicadores de conhecimento junto à população leiga. Os achados deste estudo remetem a uma reflexão acerca do aprofundamento deste assunto na graduação, envolvendo a universidade como agente integrador entre as políticas públicas de saúde e a comunidade.

O Serviço de Atendimento Móvel de Urgências foi criado com o intuito de prover assistência pré-hospitalar eficaz, diminuir o número de mortes, o tempo de internação hospitalar e as possíveis consequências da falta de atendimento precoce $e^{2,6,7,8}$. Um estudo realizado no Estado da Bahia em 2006 demonstrou que 58,7\% das ocorrências atendidas pelo Samu baiano se enquadraram em causas clínicas, com destaque para as doenças do aparelho circulatório (23,1\%). Destas, 71,5\% correspondiam a doenças hipertensivas. Já os acidentes por transporte foram responsáveis por $52,7 \%$ das ocorrências por causas externas, sendo os atropelamentos responsáveis por $61,1 \%$ e as colisões por $26,1 \%$.

$\mathrm{O}$ acionamento de um serviço médico de emergência consiste no primeiro passo de socorro da cadeia de sobrevivência do Atendimento Cardiovascular de Emergência (ACE) adulto, de acordo com as diretrizes de 2010 da American Heart Association (AHA), precedendo, inclusive, a Reanimação Cardiopulmonar (RCP) por um socorrista que esteja atuando sozinho ${ }^{10}$. No presente estudo, do total de alunos entrevistados, 20 (16,39\%) não sabiam o número de contato do Samu-192, o que é preocupante, já que isto acarretaria um atraso significante no socorro ao paciente, podendo diminuir a sua sobrevida e aumentar a chance de sequelas secundárias. Na PCR, o atraso na realização da RCP e da desfibrilação é crítico para a sobrevivência do paciente ${ }^{10,11,12}$.Um estudo realizado em Pelotas com estudantes de Medicina encontrou resultados semelhantes,pois 18,3\% não sabiam o número de contato do Samu. Deve-se levar em conta, porém, que o referido estudo não incluía estudantes dos três últimos semestres do curso de Medicina ${ }^{13}$. Mesmo em estudos de maior abrangência, pôde-se verificar que muitas pessoas não têm conhecimento do número do Samu. Pontes-Neto et al. ${ }^{14}$, pesquisando sobre o conhecimento da população brasileira sobre acidente vascular cerebral,constataram que, das 801 pessoas aleatórias entrevistadas nas cidades de Fortaleza, Salvador, São Paulo e Ribeirão Preto, apenas 277(34,6\%) listaram "192" e "193" como números do serviço médico de emergência nacional ${ }^{14}$.
Informações precisas e adequadas fornecidas pelo solicitante ao técnico auxiliar de regulação são de suma importância, pois diminuem consideravelmente o tempo decorridoatéo início das intervenções. Berdowski et al. ${ }^{15}$ constataram uma relação direta entre o reconhecimento de uma parada cardiorrespiratória (PCR) pelo técnico auxiliar de regulação (telefonista) e a sobrevida do paciente ${ }^{15}$. Se a PCR não for reconhecida precocemente pelo atendente, este irá demorar a transferir a ligação para o médico regulador, que levará mais tempo para enviar a equipe móvel de atendimento até o local, além de não fornecer adequadamente as instruções básicas de ressuscitação cardiopulmonar (RCP) pelo telefone ${ }^{10,16}$. No estudo em questão, quando os estudantes foram indagados sobre quais informações seria necessário passar à técnica de regulação (telefonista) do Samu, nenhum dos alunos forneceu a resposta correta espontaneamente, o que poderia dificultar o reconhecimento da atendente acerca da situação do paciente. Portanto, em caso de uma PCR, o sucesso da ligação dependeria do treinamento dos técnicos de regulação em realizar perguntas-chave que ajudassem no diagnóstico ${ }^{15}$. Quando os alunos foram indagados sobre a mesma questão de forma direta, respondendo com sim ou não, 62,29\% responderam corretamente, sendo reafirmada a importância do treinamento dos telefonistas do Samu. Apesar de tais dados serem necessariamente perguntados ao solicitante, é imprescindível que todos, em particular os alunos de graduação em Medicina, conheçam e compreendam a importância de fornecer tais dados, pois isto torna a ligação mais objetiva e rápida, já que, numa situação de emergência, tempo é vida.

Em relação ao nome do solicitante, os alunos do ciclo clínico se mostraram mais propensos a julgar importante esta informação do que os alunos do ciclo básico, tanto na resposta espontânea como na induzida. O nome do solicitante é uma das informações mais importantes a serem dadas ao telefonista do Samu-192, pois confere maior veracidade ao telefonema, tendo em vista o grande número de trotes de que o serviço é vítima ${ }^{17}$. Em Fortaleza, o Samu atende, em média, 2.700 ligações por dia, das quais 38-47\% (1.000 a 1.400 ligações/dia) são trotes, o que se traduz, por vezes, em deslocamento desnecessário de ambulâncias ${ }^{17}$.

Sobre o número de ambulâncias do Samu na cidade de Fortaleza, os únicos quatro entrevistados que responderam o número correto pertenciam ao ciclo básico, muito provavelmente devendo-se ao acaso a diferença significativa entre os grupos. Em Fortaleza, o Samu é composto por 20 equipes de USB e cinco equipes de USA, além de quatro motolâncias, que realizam de 200 a 300 atendimentos por dia ${ }^{17,18}$. O número li- 
mitado de ambulâncias em uma cidade restringe a quantidade de atendimentos, devendo-se priorizar os casos de maior urgência. $\mathrm{O}$ conhecimento pela população do número de ambulâncias disponíveis para atendimentoé importante para uma conscientização, a fim de que o acionamento só ocorra em casos de urgência real. Muitos estudos constataram que o número de chamadas indevidas, ou seja, pedidos de ambulância desnecessariamente, é bastante considerável, mostrando que essa é uma problemática não só do Brasil ${ }^{6,7,8}$.

Neste estudo, a maioria dos acadêmicos entrevistados sabia que havia dois tipos de ambulâncias: as que fazem o suporte básico de vida e aquelas equipadas para realizar o suporte avançado. A USA presta atendimentos a pacientes traumatizados, quaisquer que sejam as causas, e a pacientes portadores de patologias clínicas, quaisquer que sejam as etiologias, caso seja estabelecido pelo médico regulador que há risco imediato à vida ${ }^{19}$. A USB, por sua vez, presta atendimentos a pacientes traumatizados e a portadores de patologias clínicas, quaisquer que sejam as etiologias, uma vez que seja estabelecido pelo médico regulador que não há risco imediato à vida ${ }^{19}$. O conhecimento desta informação e do papel de cada tipo de ambulância é fundamental. A população deve saber que, com base nas informações passadas ao telefonista, o médico regulador irá decidir de que tipo de suporte a vítima precisa. Portanto, devem ser evitadas expressões que dificultem o estabelecimento de um diagnóstico sindrômico ou de uma hipótese diagnóstica, como "está passando mal"1. Ao médico regulador cabe a determinação da existência de risco imediato à vida, pois, somente nesta condição, salvo determinações excepcionais provenientes de órgãos superiores, serão despachadas as USA ${ }^{19}$. Esta determinação deverá ser baseada, exclusivamente, no grau de prejuízo de funções vitais, que possa acarretar risco de morte, como comprometimento da via aérea, da ventilação, da dinâmica circulatória, da função neurológica e comprometimento funcional de extremidades, etc., condições estas que devem ser informadas pelo solicitante ${ }^{19}$. Os estudantes de Medicina, em especial, devem saber dessa informação ao utilizar o serviço, pois, se souberem fazer um julgamento adequado, podem auxiliar o médico regulador a reconhecer o estado real do paciente, facilitando a decisão de qual suporte seria adequado a cada situação.

Em relação à presença do médico nas ambulâncias, os alunos do ciclo clínico acertaram mais ao afirmarem que nem toda unidade de atendimento móvel atua com um médico em seu interior. Quando perguntados sobre quantas ambulâncias, em Fortaleza, atuam com médico como membro da equipe, o percentual de erros foi muito grande $(86,1 \%)$.
Em Fortaleza, há apenas cinco USA com médico compondo a equipe ${ }^{18}$. Essa quantidade limitada de médicos intervencionistas exige que o médico regulador analise com cuidado cada solicitação, para que gerencie bem os atendimentos, de acordo com a necessidade. O Suporte Avançado de Vida tem como objetivo iniciar o maior nível de cuidado desde os primeiros momentos, na cena, e durante o transporte ${ }^{20}$. Sobre a composição de profissionais que formam a equipe de atendimento da UTI móvel, apenas seis alunos sabiam que é formada por médico, enfermeiro e motorista-socorrista ${ }^{1}$. Todos estes profissionais são peças-chave para a sobrevivência dos pacientes.

Em relação aos locais em que o Samu pode prestar atendimento, a maioria dos alunos entrevistados $(84,43 \%)$ tinha conhecimento de que o serviço atende em qualquer local, como residências, locais de trabalho e vias públicas. As ambulâncias se distribuem em 15 pontos de apoio na cidade de Fortaleza, localizados em diversos bairros da cidade ${ }^{18}$.A descentralização é uma estratégia que diminui o tempo de chegada até o local da ocorrência, embora este dependa de vários fatores, como a experiência e a capacitação profissional da equipe, condições de tráfego local, dia da semana e período do dia, tipo e número de veículos disponíveis ${ }^{21,22}$.

Estudos realizados no Brasil constataram que a maioria dos estudantes de Medicina participa, em algum momento ao longo de sua formação, de ligas acadêmicas e/ou estágios extracurriculares ${ }^{22,23}$.Neste estudo, não foi avaliado se há relação entre a participação dos estudantes em ligas acadêmicas e em estágios em Emergência e maior conhecimento sobre o Samu comparativamente.

Este estudo apresenta algumas limitações, que devem ser pontuadas. Entende-se que seria interessante comparar em separado as respostas dos alunos do primeiro semestre com as dos alunos do $11^{\circ}$ semestre do curso, para analisar o grau de retenção das informações. Isto, porém, não foi possível porque o número de estudantes avaliados em cada semestre não foi igual; por exemplo, foram entrevistados 12 acadêmicos do primeiro semestre e apenas quatro do $11^{\circ}$ semestre, já que a seleção foi aleatória, e isso limitou a comparação. Outra limitação está ligada ao universo da pesquisa.Por se tratar de uma pesquisa quantitativa, o ideal seria estudar 30\% da população, mas isto não foi possível por dificuldade de obtenção de voluntários participantes. Entretanto, compreende-se que seja válida a comparação entre os ciclos básico e clínico, já que os alunos da Universidade Federal do Ceará são expostos a dois momentos de contato com o ensino de emergências, justamente no ciclo básico e no ciclo clínico. Compreende-se que mais estudos com desenhos metodológicos mais elaborados 
precisam ser realizados em outros cursos de Medicina com o mesmo objetivo.

Diante dos achados desta pesquisa, sugere-se manter o modelo atual de ensino de emergências no primeiro e oitavo semestres.No entanto, no sexto e sétimo semestres deve haver uma programação diversificada, com conteúdo e treinamento de habilidades básicas que envolvam emergências traumáticas e não traumáticas, e que englobem emergências clínicas, cirúrgicas, psiquiátricas e em Ginecologia/Obstetrícia, com adequação do processo de ensino-aprendizagem-avaliação em laboratórios de habilidades/simulação. Nesta fase da graduação, devem ser ministrados conteúdos sobre as portarias do Ministério da Saúde do Brasil que norteiam a organização da Rede de Atenção às Urgências e Emergências no Sistema Único de Saúde ${ }^{1,2}$. Os alunos devem ter vivência prática no atendimento pré-hospitalar fixo, englobando acolhimento e classificação de risco, e móvel (Samu), na Unidade de Suporte Avançado, sob supervisão de médicos, bem como na regulação médica.

\section{CONCLUSÃO}

$\mathrm{O}$ presente estudo demonstrou que mesmo acadêmicos de Medicina, possíveis difusores de conhecimento, possuem conhecimento aquém do esperado sobre o funcionamento do serviço médico de urgência pré-hospitalar (Samu), independentemente do ciclo (básico ou clínico) em que se encontrem. Esta falta de informação pode levar a um atraso no acionamento dos serviços de emergência médica e contribuir para um desfecho clínico desfavorável. A escassa literatura acerca do tema mostra a importância da realização de novos estudos e comparação de dados em âmbito nacional, possibilitando a elaboração de novas metodologias de ensino sobre o tema durante a graduação do curso de Medicina.

\section{REFERÊNCIAS}

1. Brasil. Ministério da Saúde. Secretaria de Atenção à Saúde. Departamento de Atenção Especializada.Regulação médica das urgências. Brasília: Editora do Ministério da Saúde; 2006. 126 p.: il. (Série A. Normas e Manuais Técnicos)

2. Brasil. Ministério da Saúde. Publicação do Ministério de Saúde. Outubro de 2008. Edição n.149. ISSN 1678-8494. Disponível em: http://portal.saude.gov.br/portal/arquivos/pdf/saude_brasil_outubro_web.pdf

3. Ferreira DF, Timerman A, Stapleton E, Timerman S, Ramires JAF. Aplicação prática do ensino em emergências médicas. RevSocCardiol Estado de São Paulo. 2001;11(2):505-11.

4. Ferreira DF, Qüilici AP, Martins M, Ferreira AV, TarasoutchiF, Timerman S, et al. Essência do suporte básico de vida - perspectivas para o novo milênio: chame primeiro - chame rápido. RevSocCardiol Estado de São Paulo. 2001; 11(2):209-13

5. Ferreira AVS, Garcia E. Suporte básico de vida. RevSocCardiol Estado de São Paulo.2001;11 (2):214-25.

6. Billittier JA, Moscati R, Janicke D, Lerner Brooke E, SeymourJ, Olsson D. A multisite survey of factors contributing to medically unnecessary ambulance transports. AcadEmerg Med. 1996; 3 (11):1046-1050.

7. Gardner GJ. The use and abuse of the emergency ambulance service: some of the factors affecting the decision whether to call an emergency ambulance. Arch Emerg Med. 1990;7:81-89.

8. Clark JM, Fitzgerald G. Older people's use of ambulance services: a population based analysis. J AccidEmerg Med. 1999; 16:108-111.

9. Cabral APS, Souza WV. Serviço de Atendimento Móvel de Urgência (SAMU): análise da demanda e sua distribuição espacial em uma cidade do Nordeste. Revbrasepidemiol [online]. 2008; 11(4): 530-540. Disponível em: http:/ / www. scielo.br/scielo.php?pid=S1415-790 X 2008000400002 \& script $=$ sci_arttext.

10. Berg RA, HemphillR,Abella BS, Aufderheide TP, Cave DM,Hazinski MF, et al. Part 5: Adult Basic Life Support 2010 American Heart Association Guidelines for Cardiopulmonary Resuscitation and Emergency Cardiovascular Care. Circulation. 2010; 122(18):685-705.

11. Valenzuela TD, Roe DJ, Cretin S,Spaite DW, Larsen MP. Estimating effectiveness of cardiac arrest interventions: a logistic regression survival model. Circulation.1997; 96:3308 -3313 .

12. Hallstrom AP, Ornato JP, Weisfeldt M, Travers A, Christenson J, McBurnie MA, Zalenski R, Becker LB, Schron EB, Proschan M. Public-access defibrillation and survival after out-of-hospital cardiac arrest. N Engl J Med. 2004; 351:637646.

13. Horta BL, Pereira GAR, Silva AB, Resende BHA, Rosenthal RM, Comim C, et al. Conhecimento do estudante de Medicina sobre o Serviço de atendimento móvel de Urgência. Rev AMRIGS. 2011; 55(1):20-24.

14. Pontes-Neto OM, Silva GS, Feitosa MR, Figueiredo NL, Fiorot JA, Rocha TN, et al. StrokeAwareness in Brazil: Alarming Results in a Community-Based Study. Stroke. 2008; 39:292-96

15. Berdowski J, Beekhuis F, Zwinderman AH, Tijssen JGP, Koster RW. Importance of the first link: description and recognition of an out-of-hospital cardiac arrest in an emergency call. Circulation. 2009; 119:2096-2102. 
16. Bohm K, Rosenqvist M, Hollenberg J, BiberB,Engerstrom L, Svensson L. Dispatcher-assisted telephone-guided cardiopulmonary resuscitation: an underused lifesaving system. Eur J Emerg Med. 2007; 4(5): 256-259.

17. Prefeitura de Fortaleza. Como acionar o SAMU 192 Fortaleza [Acesso em 12 jan. 2013]. Disponível em: http:// www.Samu.fortaleza.ce.gov.br/index.php?option=com_ content\&view $=$ article\&id $=6 \&$ Itemid $=43$

18. Prefeitura de Fortaleza. As Equipes [Acesso em 12 jan. 2013]. Disponível em: http:/ / www.Samu.fortaleza.ce.gov. br $/$ index.php?option=com_content\&view $=$ article\&id $=9 \&$ Itemid $=4$

19. Lopes SLB, Fernandes RJ. Uma breve revisão do atendimento médico pré-hospitalar. Medicina (RibeirãoPreto). 1999; 32(4):381-387.

20. Roudsari BS, NathensAB, Cameron P, Civil I, Gruen RL, Koepsell TD, Lecky FE, et al. International comparison of prehospital trauma care systems. Injury. 2007; 38(9):9931000.

21. Takeda RA, Widmer JA, Morabito R. Aplicação do modelo hipercubo de filas para avaliar a descentralização de ambulâncias em um sistema urbano de atendimento médico de urgência. PesquiOper. 2004; 24(1):39-71.

22. Taquette SR, Costa-Macedo LM, Alvarenga FB. Currículo paralelo: uma realidade na formação dos estudantes de medicina da UERJ. RevBrasEduc Med. 2003; 27(3):171-6.

23. Tavares AP, Ferreira RA, França EB, Fonseca Júnior CA, Lopes GC, Dantas NGT, et al. O "Currículo Paralelo" dos estudantes de Medicina da Universidade Federal de Minas Gerais. RevBrasEduc Med. 2007; 31(3):254-65.

\section{CONTRIBUIÇÃO DOS AUTORES}

Sarah Barreira Cavalcante: idealizadora do estudo, realizou revisão bibliográfica, coletou dados, realizou análise estatística, escreveu a versão inicial do artigo científico. José Victor Gomes Costa - coletou dados, tabelou os dados, contribuiu com a escrita do artigo científico. Pedro Lucas Rodrigues Costa - coletou dados, tabelou dados, contribuiu com a escrita do artigo. Antônio Aldo Melo-Filho - orientou na metodologia científica, orientou na aplicação da estatística, revisou a versão inicial do artigo. Cláudia Regina Fernandes: revisou e escreveu a versão final do artigo, revisou a análise estatística dos dados coletados.

\section{CONFLITO DE INTERESSES}

Declarou não haver.

\section{ENDEREÇO PARA CORRESPONDÊNCIA}

Antônio Aldo Melo Filho

Departamento de Cirurgia - Faculdade de Medicina

Universidade Federal do Ceará

Rua Professor Costa Mendes, 1608, 3ํandar - Rodolfo Teófilo CEP: 60430-140 Fortaleza -Ceará

Fone: (85) 3366-8062

E-mail: aamelofilho@gmail.com 